\title{
Anti-fertility effect of hydro-alcoholic extract of fennel (Foeniculum vulgare Mill) seed in male Wistar rats
}

\author{
Esrafil Mansouri ${ }^{1}$, Majid Asadi-Samani ${ }^{2}$, Wesam Kooti ${ }^{3}$, \\ Maryam Ghasemiboroon ${ }^{4}$, Damoon Ashtary-Larky ${ }^{4}$, Fatima Alamiri ${ }^{5}$, \\ Reza Afrisham ${ }^{6}$, Zahra Hasanzadeh Noohi ${ }^{7}$ \\ ${ }^{1}$ Cellular and Molecular Research Center, Department of Anatomical Sciences, School of Medicine, \\ Ahvaz Jundishapur University of Medical Sciences, Ahvaz, Iran \\ ${ }^{2}$ Student Research Committee, Shahrekord University of Medical Sciences, Shahrekord, Iran \\ ${ }^{3}$ Student Research Committee, Kurdistan University of Medical Sciences, Sanandaj, Iran \\ ${ }^{4}$ Student Research Committee, \\ Ahvaz Jundishapur University of Medical Sciences, Ahvaz, Iran \\ ${ }^{5}$ Sophomore/Health and Medical Studies, \\ Henry Ford Early College at Henry Ford College, Dearborn, Michigan, USA \\ ${ }^{6}$ Department of Clinical Biochemistry, Faculty of Medicine, Tehran University of Medical Sciences, Tehran, Iran \\ ${ }^{7}$ Department of Biology, School of Science, Shiraz University, Shiraz, Iran \\ wesamkooti@gmail.com
}

Received: November 17, 2015 Accepted: July 25, 2016

\begin{abstract}
Introduction: The study aimed to investigate the anti-fertility effect of fennel (Foeniculim vulgare Mill) seed extract in male rats. Material and Methods: Forty Wistar rats were divided into five equal groups. The control group received distilled water and the experimental groups were orally administered $1 \mathrm{ml}$ of hydro-alcoholic extract of fennel seed in four doses of 35, 70,140 , and $280 \mathrm{mg} / \mathrm{kg} / \mathrm{b} . \mathrm{w}$. daily for 60 days. After the last gavage, the rats were anaesthetised and the caudal part of the right epididymis was used for sperm counting. After fixation of the testes, microscopic sections were prepared and histological changes were evaluated. Results: The number of spermatogonia after doses of 140 and $280 \mathrm{mg} / \mathrm{kg}$ and Sertoli cells after a dose of $140 \mathrm{mg} / \mathrm{kg}$ decreased significantly as compared with the control group $(\mathrm{P}<0.05)$. The number of primary spermatocytes and sperm count decreased significantly in the experimental groups $(70,140$, and $280 \mathrm{mg} / \mathrm{kg}$ ) when compared to the control group $(\mathrm{P}<0.05)$. Furthermore, thickening of the basement membrane, cell apoptosis, and irregular arrangement of the germinal epithelium were observed in the experimental groups. Conclusion: Hydro-alcoholic fennel seed extract at these doses could reduce reproductivity and has anti-fertility activity in male rats.
\end{abstract}

Keywords: rat, Foeniculum vulgare mill, anti-fertility effect.

\section{Introduction}

Rapid population growth is one of the main reasons for poverty and pollution in developing countries (12). Due to the importance of reproduction control and the side effects of the methods of contraception available, the utilisation of botanical substances becomes essential which are biologically effective, factorial in fertility-regulation, eco-friendly, and interventional in the natural patterns of reproduction $(4,26)$. Therefore, the provocation of reversible male infertility in humans and experimental animals with medicinal plants has also merited the consideration of researchers (12).

However, the use of such plants free of control could also have side effects (14). Therefore, it is necessary to conduct scientific research to determine their pharmaceutical properties. Fennel (Foeniculum vulgare Mill) is a herb consumed orally several ways and having several therapeutic applications. The herb is an aromatic plant belonging to the Umbelliferae family, and is an annual, biennial, or perennial plant about 
$2.5 \mathrm{~m}$ in height with feathery leaves and yellow flowers (19) and indigenous to the shores of the Mediterranean and southern Europe (2). The usable parts of the fennel plant are the root, leaf, and fruit (23). Its therapeutic properties are due to volatile compounds, phenols, and flavonoids in the plant extract. According to phytochemical studies, over 30 various terpenes and terpenoids have been identified in fennel (3), and compounds such as oestragol (methyl chavicol), fenchone, trans-anethol, and $\alpha$-phellandrene are the main constituents of the fennel seed (19). The presence of flavonoids, cumarin, and anethole has been also identified. Cumarin has anti-aromatase, oestrogenic, reductase inhibiting, and anti-androgen activities. Moreover, flavonoids and anethole are also oestrogenic compounds (4) that could depress serum levels of testosterone, and as a result, reduce sperm production. Beta-sitosterol is one of the available compounds in fennel extract and imparts effects mentioned in previous studies on sperm storage in male rats (5). Anti-inflammatory, analgesic, and anti-oxidant properties of the fennel fruit have also been reported (6). After rats received fennel extract per os, there was an increase in the size of the mammary glands, uterine tubules, ovaries, endometrium, myometrium, and vagina in female rats and an increase in the protein concentration in the seminal vesicles and in the prostate gland in male rats (8). Additional properties of the extract are oestrogenic, stimulating milk secretion, facilitating childbirth, increasing sexual desire (9), and relieving menstrual pain (2). Considering available reports regarding the anti-fertility effects of fennel compounds, and also the paucity of information about the effects of this plant on fertility, the present study aimed at investigating the effects of the hydro-alcoholic extract of fennel seed on the number of spermatogenic cells and testis structure in male rats. The results of the study could serve as a step toward the development of a mechanism-based approach for the management of fertility or infertility in humans and animals.

\section{Material and Methods}

Forty male Wistar rats, 8 weeks old and weighing 170-220 g, were obtained from the Animal House of Ahvaz University of Medical Sciences, Khoozastan province, Iran. The rats were housed in standard cages, maintained under standard conditions (12 h light/ dark cycle; $23 \pm 2{ }^{\circ} \mathrm{C}$ temperature; $35 \%-60 \%$ relative humidity), and provided with standard laboratory chow and water ad libitum.

Preparation of extract. The extract of fennel seeds was prepared by the maceration method. One hundred grams of powdered fennel seeds was soaked in $500 \mathrm{~mL}$ of $70 \%$ ethanol and stirred intermittently for $48 \mathrm{~h}$ at room temperature. The material was filtered using sterile cotton wool and Whatman (No. 1) filter paper; the pooled filtrates obtained were dried in the oven at $40^{\circ} \mathrm{C}$ for $48 \mathrm{~h}$ and the extracted powder was kept at $4^{\circ} \mathrm{C}$ until used $(1,13,32)$. The required concentration of the extract was obtained by dilution of the powder with distilled water.

Animals and treatment protocol. The rats were divided into five equal groups. The control group received $1 \mathrm{~mL}$ of distilled water (as an extraction solvent), and the experimental groups were given $1 \mathrm{~mL}$ of hydro-alcoholic extract of fennel seed by oral gavage at respective doses of $35,70,140$, and $280 \mathrm{mg} / \mathrm{kg}$ b.w. daily for 60 days $(10,18)$. The rats were deeply anaesthetised by xylazine $(10 \mathrm{mg} / \mathrm{kg})$ and ketamine (60 mg/kg) (Alfasan, the Netherlands) $24 \mathrm{~h}$ after the last dose.

Surgery and sample preparation. The testes and epididymis were dissected out and then the epididymis duct was carefully separated from the testes.

Histological analysis. The testes were fixed in Bouin's fluid, dehydrated through increasing concentrations of ethanol, and embedded in paraffin. Then, $5 \mu \mathrm{m}$-sections (five from each animal) were stained with haematoxylin and eosin. The sections were used (six tubules in each section) to determine the diameter of the seminiferous tubules, thickness of epithelium, spermatogonia cell count, primary spermatocyte, and Sertoli cells under an Olympus 3H-Z light microscope (Olympus, Japan). In this part, the seminiferous tubules were examined in stage VIII based on the previous study (20). In order to measure the diameter of the tubules and thickness of the epithelium, a Motic stereo camera and Motic Image Plus 2.0 software were also used (Motic, China).

Counting sperm. The sperm from the caudal portion of the epididymis were released by fragmentation of the epididymis in $1 \mathrm{~mL}$ of physiological saline. When the epididymis became totally homogenous by mixing and diluting with the saline at a ratio of $1: 100$, it was used for sperm counting using a Neubauer chamber and a light microscope. In order to reduce the possibility of error, all of the four parts (16 pieces per part) were counted and then their mean was calculated and multiplied by $10^{6}$ and set as the total number of sperm (11).

Statistical analysis. All data are expressed as the mean \pm SE. Statistical significance of differences was assessed with one-way ANOVA by SPSS for Windows (version 15) (IBM, USA) followed by the LSD test. $\mathrm{P}<0.05$ was assumed as statistically significant.

\section{Results}

Histological examination. Microscopic study of cross sections of control testes indicated that the epithelium structure did not show any abnormalities (Fig. 1A). Compared with the control group, the tissue structure of seminiferous tubules in the experimental groups exhibited some changes such as basement membrane thickening and reduction of seminiferous 
cells. Vacuolisation of tubules in the inner space and the irregular arrangement of seminiferous cells, as well as apoptosis, pyknotic nuclei, and hyperaemia of testis tissue in the experimental groups were evident. (Fig. 1B-E).

Morphometric examination. Comparison of testis tissue sections indicated that the thickness of the epithelium and diameter of seminiferous tubules in the experimental group did not differ significantly from those in the control group $(\mathrm{P}>0.05)$ (Table 1).
A reduction in spermatogonia cell count was demonstrated in the group treated with the extract compared with the control group. According to statistical analysis, this reduction in 140 and $280 \mathrm{mg} / \mathrm{kg}$ dosages was significant $(\mathrm{P}<0.05)$ (Fig. 2).

Sertoli cells count showed a reduction in their number in the experimental groups compared with the control group that was significant at $140 \mathrm{mg} / \mathrm{kg}$ dosage $(\mathrm{P}<0.05)$ (Fig. 3).
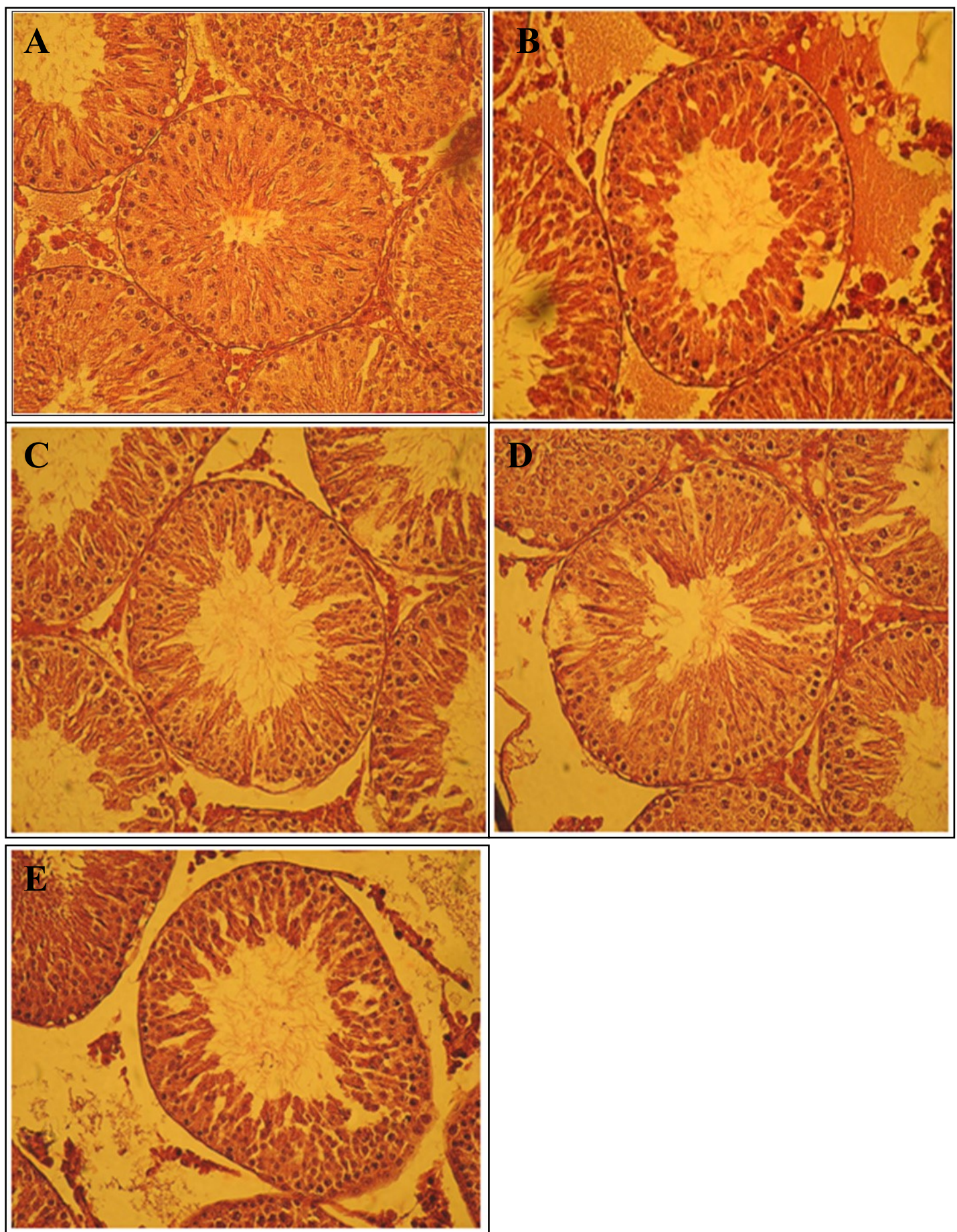

Fig. 1. Photomicrograph of seminiferous tubules in rats: A - control group; B - experimental group (35 mg/kg); C - experimental group $(70 \mathrm{mg} / \mathrm{kg}) ; \mathrm{D}$ - experimental group $(140 \mathrm{mg} / \mathrm{kg}) ; \mathrm{E}-$ experimental group $(280 \mathrm{mg} / \mathrm{kg})$. HE, 300× 
Table 1. Changes in thickness of epithelium and diameter of seminiferous tubules in experimental and control groups

\begin{tabular}{lll}
\hline Group & Diameter of seminiferous tubules & Thickness of epithelium \\
\hline Control & $128 \pm 2.7$ & $40 \pm 1.9$ \\
\hline $\begin{array}{l}\text { Experimental } 1 \\
35(\mathrm{mg} / \mathrm{kg})\end{array}$ & $136 \pm 2.3$ & $38 \pm 2.6$ \\
\hline $\begin{array}{l}\text { Experimental } 2 \\
70(\mathrm{mg} / \mathrm{kg})\end{array}$ & $135 \pm 3.3$ & $36 \pm 1.4$ \\
\hline $\begin{array}{l}\text { Experimental } 3 \\
140(\mathrm{mg} / \mathrm{kg})\end{array}$ & $131 \pm 3.2$ & $37 \pm 1.4$ \\
\hline $\begin{array}{l}\text { Experimental } 4 \\
280(\mathrm{mg} / \mathrm{kg})\end{array}$ & $136 \pm 3$ & $35 \pm 1.4$ \\
\hline
\end{tabular}

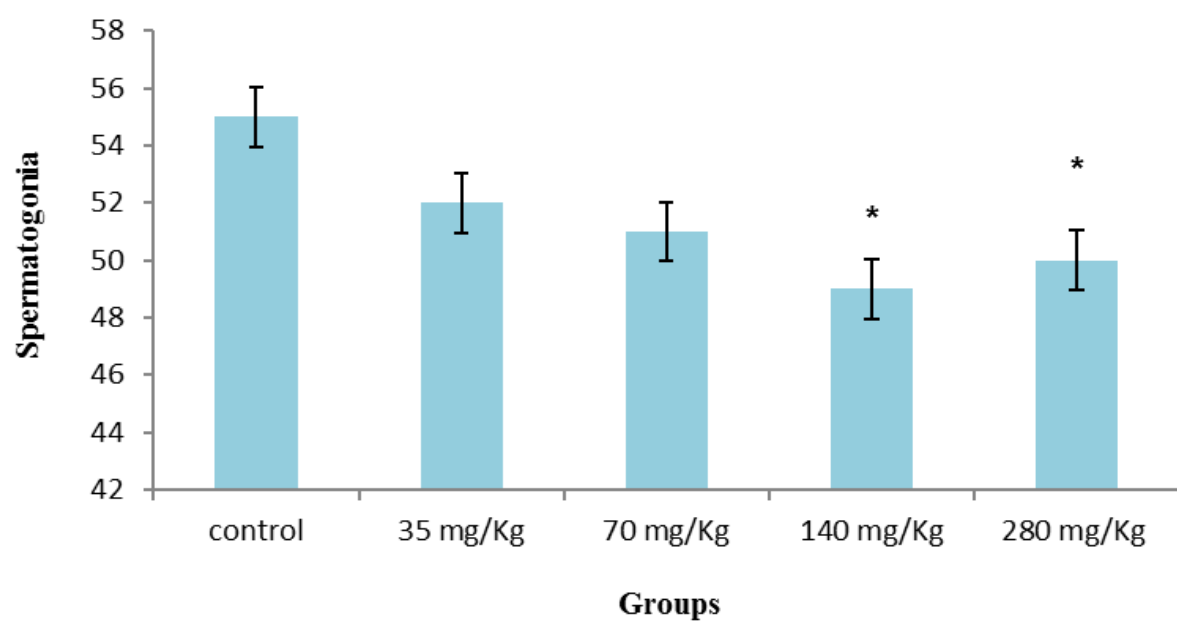

Fig. 2. Comparison of mean $\pm \mathrm{SE}$ of spermatogonia cells between experimental and control animals $(\mathrm{n}=8)$; $* \mathrm{P}<0.05$

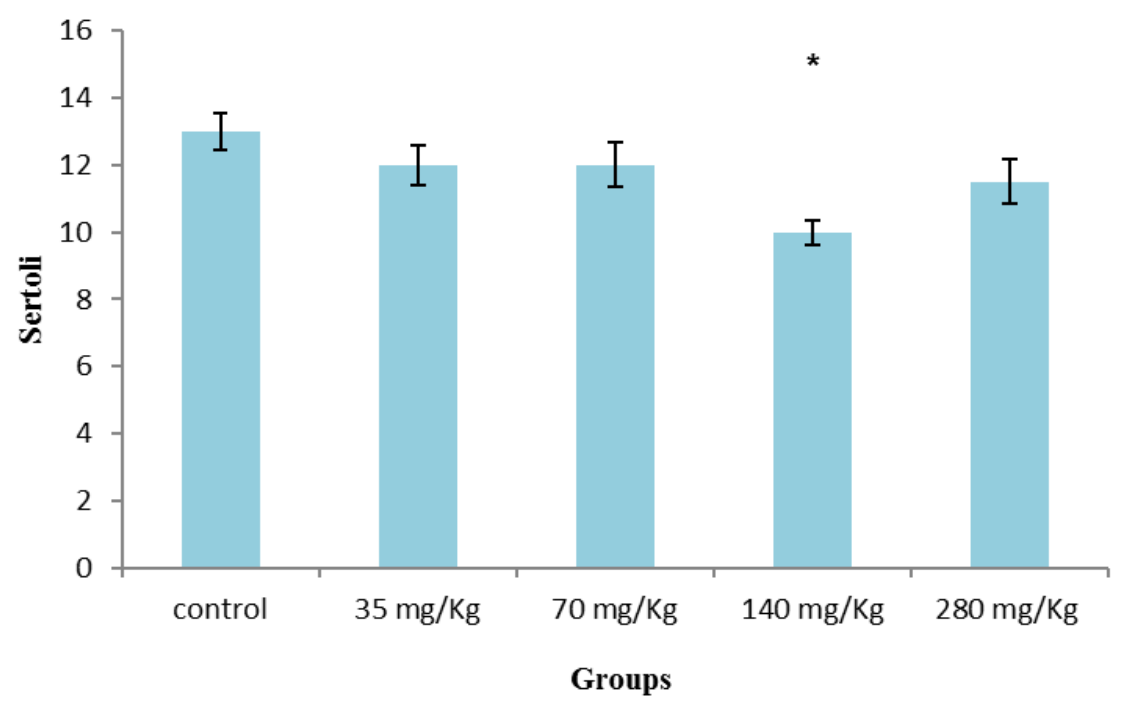

Fig. 3. Comparison of mean number of Sertoli cells between experimental and control animals $(\mathrm{n}=8) ;{ }^{*} \mathrm{P}<0.05$

A review of primary spermatocyte cell counts in the experimental groups suggested that compared to the control group, the number of these cells was reduced, and this reduction was significant in the experimental groups receiving 70,140 , and $280 \mathrm{mg} / \mathrm{kg}$ doses of fennel extract $(\mathrm{P}<0.05)$ (Fig. 4).
Sperm count. The effects of the fennel seed extract in various concentrations on sperm count led to results indicating that compared with the control group, epididymis sperm in the experimental groups significantly decreased $(\mathrm{P}<0.05)$ (Fig. 5). 


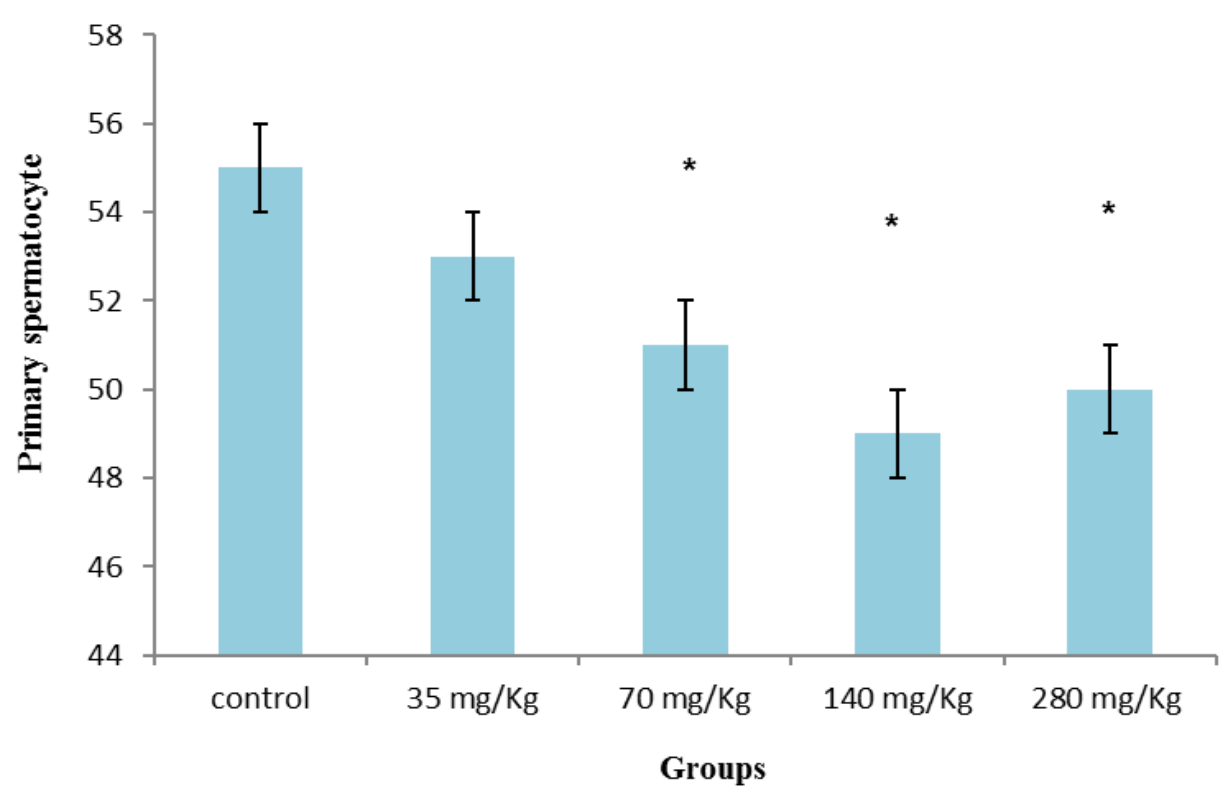

Fig. 4. Comparison of mean number of primary spermatocyte cells between experimental and control animals $(\mathrm{n}=8) ; * \mathrm{P}<0.05$

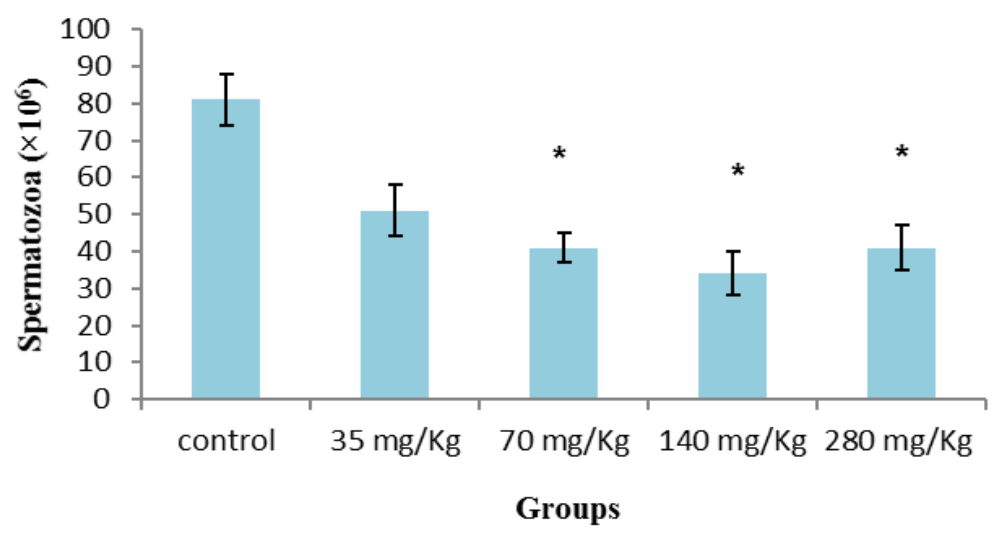

Fig. 5. Comparison of mean number of sperm cells between experimental and control animals $(\mathrm{n}=8) ; * \mathrm{P}<0.05$

\section{Discussion}

Excessive population of rodents is an important problem because they can be carriers of many serious diseases. Limiting reproduction of rodents through the use of natural herbal extracts seems to be useful (15). The testes, epididymis, and sex hormones are part of the reproductive system. The testes undertake both organised and vital processes of spermatogenesis and steroidogenesis (21). In the present research, histological and morphometrical studies of testis tissue indicated a reduction in sperm cell count in the experimental groups compared with the control group suggestive of an effect of hydro-alcoholic extract of fennel seed on the spermatogenesis process and fertility. According to the results of the present study, oral administration of hydro-alcoholic extract of fennel seed at high doses caused a reduction in spermatogonia and Sertoli cells, and a significant reduction in primary spermatocytes in the experimental groups compared with the control group. These observations are consistent with the findings of Dehghani et al. (4). Empty spaces observed within germinal epithelium seminiferous tubules in the treatment groups also could be the result of loss of germ cells.

One of the main reasons for reduction in the cell count could be existing compounds in the herb extract that inhibited cell division, particularly flavonoids. According to the findings of recent studies, flavonoids could restrain DNA replication and inhibit cell division, as well as stimulate apoptosis by affecting cell DNA (24). In the present study inhibition of folliclestimulating hormone (FSH) secretion was probably caused by fennel extract. FSH plays a role in stimulation of cell division, puberty, secretion capacity, the spermatogenesis process and the cytoskeleton arrangement of Sertoli cells, promoting cell differentiation into primary spermatocytes, and 
inhibiting apoptosis of spermatogonia and spermatocyte cells (26).

Among other results obtained in this research, reduction in epididymal sperm in rats treated with fennel seed extract is consistent with results of previous studies. The study of the effects of the aqueous extract of fennel seed by Rezaei Ahvanouei et al. (29) indicated that the administration of 140 and $280 \mathrm{mg} / \mathrm{kg} / \mathrm{b}$.w. of the extract caused a significant reduction in sperm count after 15 days. The process of producing mature sperm from undifferentiated cells, called spermatogenesis, is a complex operation performed and supported by somatic Sertoli cells within seminiferous tubules (21). In this study, the reduction in Sertoli cells and primary spermatocyte count was due to the reduction of epididymal sperms. Sertoli cells undertake structural support and feed germ cells. They allow kariyokinesis, cytokinesis, and the differentiation process of spermatozoids by producing growth factors such as activin in the presence of ionised calcium (29). Therefore, their count reducing, some disorder in spermatogenesis and reduction in the produced sperm may be expected. Among other factors lowering epididymal sperm count, inhibition of gonadotropins and testosterone secretion proceed from application of the fennel extract, and were reported previously (29). In a study by Ahvanouei et al. the authors suggested that the aqueous extract of fennel seed decreases the content of testosterone and gonadotropins in groups treated with it (30). Moreover, results obtained through the research of Dehghani et al. (4) also suggest a reduction in serum testosterone after 30 days of treatment with fennel extract. According to the available data, the beginning and continuation of the spermatogenesis process is controlled by gonadotropin hormones such as FSH and luteinising hormone (LH) (21). The presence of testosterone also seems necessary for most spermatogenesis stages, especially for meiosis, as well as spermiogenesis (transformation of a spermatid into a spermatozoon) (25).

It is clear that any change in gonadotropin rate and any disorder in testosterone production may be accompanied by changes in spermatogenesis that will ultimately lead to a disorder in sperm production. In addition, analysis of light microscope tissue sections indicates an increase in thickness of the basement membrane of seminiferous tubules in the experimental group compared with the control group. The thickness of the basement membrane plays an important role in spermatogenesis (31). The thickening of the basement membrane of the seminiferous tubules accompanied by disorders in spermatogenesis and reduction in sperm production observed by Shayn et al. (33) is consistent with the present study.

In conclusion, our findings suggest that the application of hydro-alcoholic extract of fennel seed could induce some changes in the spermatogenesis process and in male reproduction activity. Easy access and fewer side effects are the advantages of medicinal herbs compared to chemical drugs. Therefore, fennel could be considered a natural contraceptive drug for animals.

Conflict of Interests Statement: The authors declare that there is no conflict of interests regarding the publication of this article.

Financial Disclosure Statement: The results presented are part of a research project approved and conducted by the Student Research Committee of Ahvaz Jundishapur University of Medical Sciences, with the financial support of the Deputy Vice-chancellor for Research Affairs of AJUMS.

Animal Rights Statement: The authors declare that the experiments on animals were conducted in accordance with Local Ethical Committee laws and regulations as regards care and use of laboratory animals. The study was carried out in accordance with principles of laboratory care established by the Ethics Committee of Ahvaz Jundishapur University of Medical Sciences.

\section{References}

1. Afrisham R., Aberomand M., Ghaffari M.A., Siahpoosh A., Jamalan M.: Inhibitory effect of Heracleum persicum and Ziziphus jujuba on activity of alpha-amylase. J Bot 2015, 2015, Article ID 824683.

2. Birdane F.M., Cemek M., Birdane Y.O., Gulcin I., Buyukokuroglu M.E.: Beneficial effects of Foeniculum vulgare on ethanol-induced acute gastric mucosal injury in rats. World J Gastroenterol 2007, 13, 607-611.

3. Csupor-Löffler B., Hajdú Z., Zupkó I., Réthy B., Falkay G., Forgo P.: Antiproliferative effect of flavonoids and sesquiterpenoids from Achillea millefolium s.l. on cultured human tumour cell lines. Phytother Res 2009, 23, 672-676.

4. Dehghani F., Panjehshahin M.R., Mirzaee Z., Mehrabani D.: Effect of Foeniculum vulgare organic extract on blood sex hormones and reproductive tissues of male rats. J Appl Anim Res 2005, 27, 17-20.

5. Dhanapal R., Ratna J.V., Sarathchandran I., Gupta M.: Reversible antispermatogenic and antisteroidogenic activities of Feronia limonia fruit pulp in adult male rats. Asian Pac J Trop Biomed 2012, 2, 684-690.

6. Dobashi M., Fujisawa M., Yamazaki T., Okada H., Kamidono S.: Distribution of intracellular and extracellular expression of transforming growth factor-b1 (TGF-b 1) in human testis and their association with spermatogenesis. Asian J Androl 2002, 4, 105-109.

7. Ghasemiboroon M., Ghafourian Boroujerdnia M., Ahangarpoor A., Kooti W., Hasanzadeh Noohi Z., Noori Ahmad Abadi M.: The effect of hydro-alcoholic extract of celery (Apium graveolens) leaves on serum level of testosterone, FSH and LH in male rats. ZUMS J 2014, 22, 49-57.

8. Grootegoed J.A., Siep M., Baarends W.M.: Molecular and cellular mechanisms in spermatogenesis. Best Pract Res Clin Endocrinol Metab 2009, 14, 331-343.

9. Hosseinzadeh H., Karimi G.R., Ameri M.: Effects of Anethum graveolens L. seed extracts on experimental gastric irritation models in mice. BMC Pharmacol 2002, 2: 21 
10. Jalali A.S., Hasanzadeh S., Malekinejad H.: Achillea millefolium inflorescence aqueous extract ameliorates cyclophosphamideinduced toxicity in rat testis: stereological evidences. Chin J Nat Med 2012, 10, 247-254.

11. Khaki A., Peyravi T.: Effect of ciprofloxacin on cauda epididiyms sperm quality and apoptosis. Urmia Med J 2008, 19, 29-35.

12. Kooti W., Ghasemiboroon M., Ahangarpoor A., Hardani A., Amirzargar A., Asadi-Samani M., Zamani M.: The effect of hydro-alcoholic extract of celery on male rats in fertility control and sex ratio of rat offspring. J Babol Univ Med Sci 2014, 16, 43-49.

13. Kooti W., Ghasemiboroon M., Asadi-Samani M., Ahangarpoor A., Abadi M.N.A., Afrisham R., Dashti, N.: The effects of hydroalcoholic extract of celery on lipid profile of rats fed a high fat diet. Adv Environ Biol 2014, 8, 325-330.

14. Kooti W., Ahangarpoor A., Ghasemiboroon M., Sadeghnezhadi S., Abbasi Z., Shanaki Z., Hasanzadeh-Noohi Z., Asadi-Samani M.: Effect of Apium graveolens leaf extract on serum level of thyroid hormones in male rat. J Babol Univ Med Sci 2014, 16, 44-50.

15. Kooti W., Ghasemiboroon M., Asadi- Samani M., Ahangarpoor M., Zamani M., Amirzargar A., Hardani, A.: The effect of hydroalcoholic extract of celery leaves on the delivery rate (fertilization and stillbirths), the number, weight and sex ratio of rat offspring. Adv Environ Biol 2014, 8, 824-830.

16. Kooti W., Farokhipour M., Asadzadeh Z., Ashtary-Larky D., Asadi-Samani M.: The role of medicinal plants in the treatment of diabetes: a systematic review. Electronic Physician 2016, 8, 1832-1842.

17. Kooti W., Mansori E., Ghasemiboroon M., Harizi M., Amirzargar A.: Protective effects of celery (Apium graveolens) on testis and cauda epididymal spermatozoa in rat. Iran J Reprod Med 2014, 12, 365-366.

18. Kooti W., Mansouri E., Ghasemiboroon M., Harizi M., AshtaryLarky D., Afrisham R.: The effects of hydroalcoholic extract of Apium graveolens leaf on the number of sexual cells and testicular structure in rat. Jundishapur J Nat Pharm Prod 2014, 9, e17532.

19. Kooti W., Moradi M., Ali Akbari S., Sharafi-Ahvazi N., AsadiSamani M., Ashtary-Larky D.: Therapeutic and pharmacological potential of Foeniculum vulgare Mill: a review. J Herbmed Pharmacol 2015, 4, 1-9.

20. Leblond C.P., Clermont Y.: Definition of the stages of the cycle of the seminiferous epithelium in the rat. Annal New York Acad Sci 1952, 1, 55, 548-573.

21. Lucinda L.M., Rocha C.B., Reboredo M.M., Faria V.C., Sá R.: Assessment of sperm production and reproductive organs of Wistar rats to long-term exposure of Caesalpinia ferrea. An Acad Bras Ciênc 2010, 82, 907-914.
22. Malini T., Vanithakumari G., Megala N., Anusya S., Devi K., Elango V.: Effect of Foeniculum vulgare Mill. seed extract on the genital organs of male and female rats. Indian J Physiol Pharmacol 1985, 29, 21-26.

23. Mansouri E., Kooti W., Bazvand M., Boroon M.G., Amirzargar A., Afrisham R., Afzalzadeh M.R., Ashtary-Larky D., Jalali N.: The effect of hydro-alcoholic extract of Foeniculum vulgare Mill on leukocytes and hematological tests in male rats. Jundishapur J Nat Pharm Prod 2015, 10, e18396.

24. McLachlan R., Wreford N., O'Donnell L., De Kretser D., Robertson D.: The endocrine regulation of spermatogenesis: independent roles for testosterone and FSH. J Endocrinol 1996, 148, 1-9.

25. Miura, C., Miura T., Yamashita M., Yamauchi K., Nagahama, Y.: Hormonal induction of all stages of spermatogenesis in germ-somatic cell coculture from immature Japanese eel testis. Develop Growth Different 1996, 38, 257-262.

26. Montaserti A., Pourheydar M., Khazaei M., Ghorbani R.: Antifertility effects of Physalis alkekengi alcoholic extract in female rat. Iran J Reprod Med 2007, 5, 13-16.

27. Oktay M., Gülçin İ., Küfrevioğlu Ö.İ.: Determination of in vitro antioxidant activity of fennel (Foeniculum vulgare) seed extracts. LWT-Food Sci Technol 2003, 36, 263-271.

28. Rather M.A., Dar B.A., Sofi S.N., Bhat B.A., Qurishi M.A.: Foeniculum vulgare: A comprehensive review of its traditional use, phytochemistry, pharmacology, and safety. Arabian J Chem 2012, 1, 49-56.

29. Rezaei Ahvanouei T., Shiravi A., Keramati K.: Study of IP injection of Foeniculum vulgare Mill seed aqua extract on spermatogenesis and histologic changes of testis in male Wistar rats. Anim Biol 2009, 2, 19-26.

30. Rezaei Ahvanouei T., Shiravi A., Keramati K.: Study of IP injection of "Foeniculum vulgare Mill" seed aqueous extract on gonadotropic and testosterone hormones in male Wistar rats. Anim Biol 2009, 1, 39-45.

31. Sadeghi Pour H.R., Haeri Rohani S.A., Parandin R., Vosooghi M., Sepehri H., Hadji Akhoondi A., Khanavi M.: Evaluation of antifertility effect of the seed oil constituents of Iranian species of Melia azedarach L. in male rats. J Nat Med 2006, 2, 23-29.

32. Sadegh-Nejadi S., Aberomand M., Ghaffari M.A., Mohammadzadeh G., Siahpoosh A., Afrisham R.: Inhibitory effect of Ziziphus Jujuba and Heracleum Persicum on the activity of partial purified rat intestinal alphaglucosidaseenzyme. J Mazandaran Univ Med Sci 2016, 25, 135-146.

33. Shayan Z., Ayatollahi S.M.T., Zare N., Moradi F.: Prognostic factors of first birth interval using the parametric survival models. Iran J Reprod Med 2014, 12, 125-130. 